\title{
Effects of Compression Stockings on the Risk of Obstructive Sleep Apnea (OSA) in Hemodialysis Patients
}

\author{
Astilia Astilia ${ }^{1}$, Ria Bandiara ${ }^{2}$, Cecep Eli Kosasih ${ }^{3}$, Kusman Ibrahim $^{3}$ \\ ${ }^{1}$ Postgraduate Nursing Program, Faculty of Nursing, Universitas Padjadjaran, Indonesia \\ ${ }^{2}$ Faculty of Medicine, Universitas Padjadjaran, Indonesia \\ ${ }^{3}$ Faculty of Nursing, Universitas Padjadjaran, Indonesia \\ Corresponding Author: Astilia Astilia (astilia_chania@yahoo.co.id)
}

Revised: 28 July 2020

Accepted: 17 August 2020

\begin{abstract}
Background: Obstructive Sleep Apnea (OSA) in hemodialysis patients is a sleep disorder that involves stopping or decreasing airflow to breathe during sleep due to excess fluid in the leg. Compression Stockings (CSs) with $30-40 \mathrm{mmHg}$ are highpressure elastic stockings that are assumed to reduce foot fluid accumulation during the day and to prevent overnight fluid shifting to the neck.

Purpose: The study aimed to determine the effects of $30-40 \mathrm{mmHg}$ CSs on the risk of OSA in hemodialysis patients.

Method: This study used a pre-posttest quasi-experimental design with a control group. Purposive sampling was applied to recruit 68 hemodialysis patients to participate in the study. The risk score of OSA was measured using the STOP-Bang questionnaire. Highpressure CSs were given for one week to the intervention group with two OSA measurements on the 4th and 7th days. The data then were analyzed using the Post Hoc Wilcoxon test and the Mann Whitney test.

Results: There was a significant difference between the risk score for OSA before and after the use of 30-40 $\mathrm{mmHg}$ CSs in the intervention group on day $4(p=0.000)$, and day 7 ( $p=0.000)$, compared to the control group.

Conclusion: High-pressure CSs decreased the risk of OSA in hemodialysis patients by avoiding fluid retention in the legs, thus preventing fluid shifting to the neck. CSs could be recommended as an alternative to prevent the risk of OSA in hemodialysis patients.
\end{abstract}

Keywords: Compression stockings; fluid shift; hemodialysis; obstructive sleep apnea

How to Cite: Astilia, A., Bandiara, R., Kosasih, C.E., \& Ibrahim, K. (2020). Effects of compression stockings on the risk of Obstructive Sleep Apnea (OSA) in hemodialysis patients. Nurse Media Journal of Nursing, 10(2), 211-220. doi:10.14710/nmjn.v10i2.24527

Permalink/DOI: https://doi.org/10.14710/nmjn.v10i2.24527

\section{BACKGROUND}

One of the efforts to treat Chronic Kidney Disease (CKD), especially for patients with stage 5 or Terminal Kidney Failure (TKF), is through Kidney Replacement Therapy (KRT). Hemodialysis is a replacement therapy for kidney function that uses a special 
device to remove toxic uremic and regulate the body's electrolyte fluid (Ministry of Health Republic of Indonesia, 2013). According to the Indonesian Renal Registry (IRR) (2018), the prevalence of TKF accounts for $92 \%$ of all renal failure patients undergoing hemodialysis therapy. In 2018, the total of hemodialysis patients had doubled compared to 2017 which was 66,433 (IRR, 2018).

One of the most frequent complications in hemodialysis patients is sleep disorders, with an average prevalence of 50-80\%. OSA is one of the sleep problems in dialysis patients. OSA is a chronic condition due to narrowing of the upper airway that occurs repeatedly during sleep and results in collapse, recurrent nocturnal asphyxia, fragmented sleep, fluctuations in blood pressure, rapid heart rate, and increased sympathetic activities due to poor sleep quality (Ogna et al., 2015). The prevalence of sleep apnea in CKD patients occurs 10 times higher than that in the general population (Abuyassin, Sharma, Ayas, \& Laher, 2015). This is supported by the research of Wali et al. (2015) in Saudi Arabia which report that sleep disorders in TKF patients who experience OSA are about 10 times.

OSA in TKF patients results from excess fluid caused by an overnight rostral fluid shift. During the day, liquids tend to accumulate in the legs due to gravity in an upright position or sitting. When lying supine at night, water redistributes to the upper part of the body including soft neck tissue so that it narrows the upper airways, which increases the risk of OSA (Silva, Santos, Drager, Coelho, \& Elias, 2017). Increased fluid in the neck can narrow the upper airway by enhancing the pressure of extracellular tissue directly and capillary hydrostatic pressure. This increasing pressure facilitates fluid movement from intravascular to interstitial space, which can cause an enlargement of the upper airway mucosa (Redolfi et al., 2011a). As a result of the enlarged upper airway, there is a reduction in recurrent oxygen saturation creating increased oxidative stress and stimulating the sympathetic system that causes hypertension and increased cardiovascular risk.

OSA is often undiagnosed because OSA usually cannot be detected in routine patient examinations (Budiarsa, 2016). Most people who have experienced OSA do not realize or even ignore it because it only occurs during sleep and is considered a trivial or harmless thing. However, Kerns et al. (2018) report that OSA is a significant risk factor for mortality in dialysis patients. Therefore, diagnosing OSA is important in the management of hemodialysis patients with a high risk of cardiovascular morbidity and mortality as OSA is a treatable condition. Optimizing therapy to overcome OSA problems can improve the patients' sleep quality. On the other hand, untreated OSA can contribute to cardiovascular mobility and mortality resulting in decreased patients' quality of life (dos Reis Santos et al., 2013).

Alternative interventions can be given to overcome OSA in patients with excess fluid, namely Compression Stockings (CSs). These interventions have been carried out in some developed countries. CSs are elastic socks that are widely used for the treatment of varicose veins and edema. Based on the research of Silva et al. (2017), CSs prevent the movement of fluid into the lower limbs and also from the intracellular to the extracellular space of the torso. Therefore, the upward pressure given by CSs partially 
counteracts gravitational forces, avoiding swelling of the legs, and maintains more fluid in the intracellular space which tends to move freely to other areas of the body. As a result, there is a reduction in the amount of fluid reaching the neck, which partially prevents the buildup of edema in the upper airway at night.

Based on several existing OSA studies, the CSs used is a medium pressure of 20-30 mmHg (Redolfi, Arnulf, Pottier, Bradley, \& Similowski, 2011b; Redolfi et al., 2011a; Silva et al., 2017; White, Lyons, Yadollahi, Ryan, \& Bradley, 2015) whereas according to Nelson \& Bell-Syer (2012), high-pressure CSs of 30-40 $\mathrm{mmHg}$ is more effective than low and medium pressure compression. The use of CSs pressure of $30-40 \mathrm{mmHg}$ can significantly reduce the symptoms of lower limb pain, edema, activity intolerance, and sleep disorders (Özdemir, Sevim, Duygu, Tuğral, \& Bakar, 2016). This is supported by the International Society of Lymphology (2013) claiming that the gradual use of CS, especially using high pressure, can increase extremity oxygenation. The OSA research in hemodialysis patients has never been extensively conducted in Indonesia using compression stockings of 30-40 $\mathrm{mmHg}$. Therefore, a study to investigate whether 30-40 $\mathrm{mmHg}$ CSs reduce the risk of OSA needs to be carried out.

\section{PURPOSE}

This research aimed to determine the effects of compression stockings of $30-40 \mathrm{mmHg}$ on the risk of Obstructive Sleep Apnea (OSA) in hemodialysis patients.

\section{METHODS}

\section{Design and samples}

This study was quantitative research using a pretest-posttest quasi-experimental design with a control group. The researchers used a purposive sampling method to recruit the samples who met the inclusion and exclusion criteria. The inclusion criteria were the patients undergoing hemodialysis twice a week for more than 3 months, aged $>25$ years old, composmentis, at intermediate risk, and have high risk of OSA based on the STOPBang questionnaire, and hypertension. On the other hand, the exclusion criteria were the patients with neurological, musculoskeletal, and upper respiratory tract disorders, totally assisted daily activities, and had current history of smoking or alcohol abuse, wounds, or foot skin infections. The respondents were then divided with equally same number to the intervention and control groups. The respondent's flow chart is shown in Figure 1.

\section{Intervention}

The measurement (pre-test) was carried out on the first day of the study by filling out the STOP-Bang questionnaire sheet. In the intervention group, the researchers explained the procedure for using and releasing knee-high CSs and asking the respondents or respondents' families to carry out the procedure that was modeled by the researchers. On the other hand, the control group respondents used knee-high socks (Figure 1). Researchers and respondents agreed to use CSs every day after waking up in the morning and being released while sleeping at night with minimum use of 9 hours/day for one week. The CSs could be released during bathing, ablution, and prayers, and reused after the activities were done. The researchers contacted the respondents or respondents' families to validate the use of CSs by telephone and checklist, the starting and ending time for using CSs, and the total use of CSs every day. Re-measurement 
(post-test) was carried out 2 times according to the respondents' hemodialysis schedule, on the 4th day and 7th day of the use by filling out the STOP-Bang questionnaire.

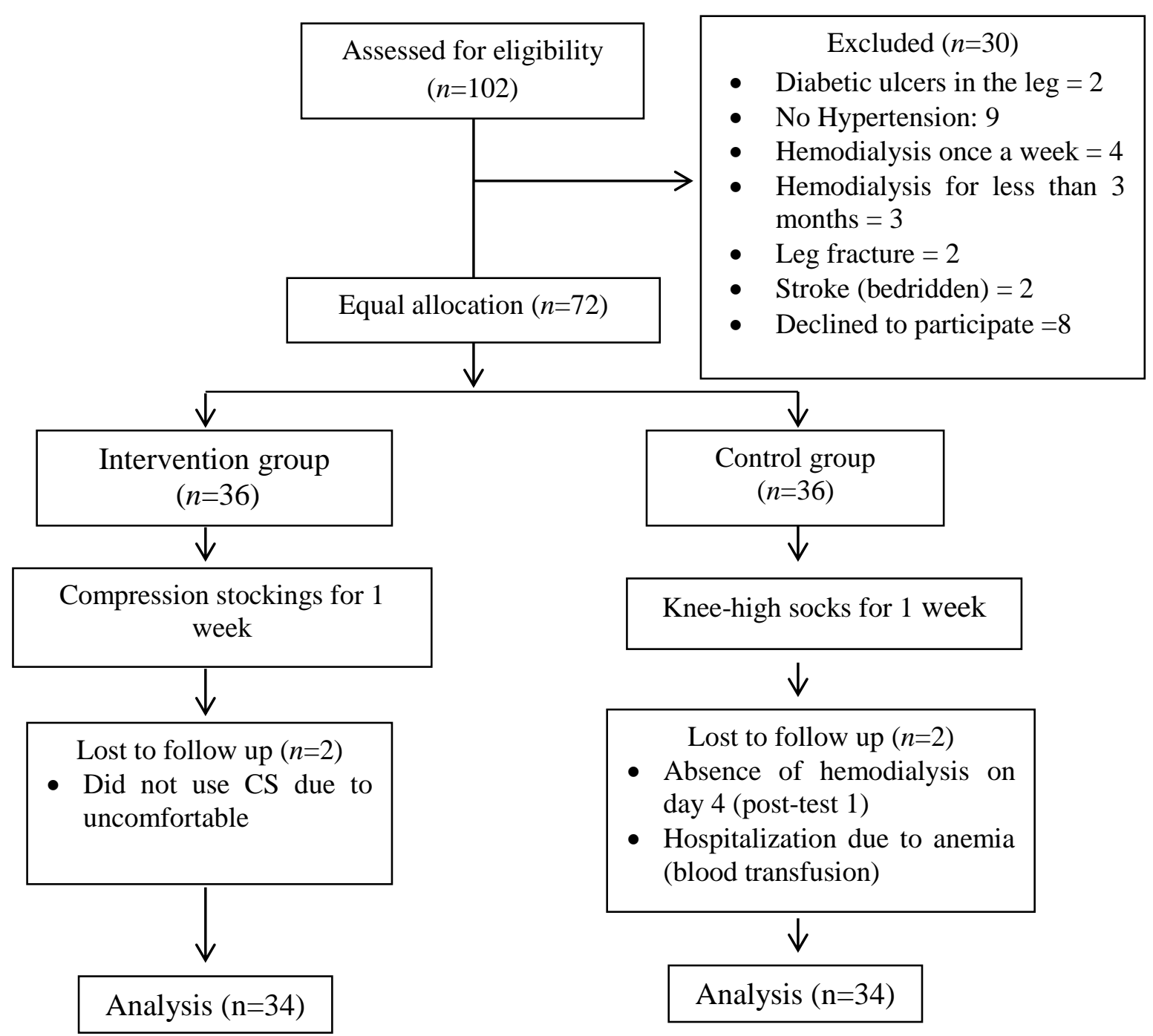

Figure 1. Respondents' flow chart

\section{Measurements}

The measuring instrument used in this research was the STOP-Bang Questionnaire (SBQ), which is a simple and effective questionnaire, has moderate performance in diagnosing OSA, and has been widely used due to high sensitivity compared to other OSA questionnaires. The STOP-Bang questionnaire was published in 2008, consisted of eight conceptual questions based on the Berlin questionnaire published in 1999. The conceptual questions were developed based on the symptoms and clinical characteristics of OSA including snoring, tiredness, observed apnea, blood pressure, body mass index (BMI), age, neck circumference, and gender (Chung et al., 2008). The risks of OSA were divided into three categories, namely low risk, intermediate risk, and high risk. 
The STOP-Bang questionnaire had been tested for validity $(r=0.876)$ and reliability (Cronbach alpha of 0.962) (Anwar, Tursina \& Rosadi, 2017). This study also used Compression Stocking (CSs) with the brand of VARITEKS ® type 902 with a length below the knee for all sexes, type class III: $30-40 \mathrm{mmHg}$.

\section{Data analysis}

The Friedman test was used to analyze the mean difference before and after the intervention and continued with the post hoc Wilcoxon test to see the development of OSA risk on days 4 and 7 . The Mann Whitney test was also used to compare the mean differences between the intervention and the control groups.

\section{Ethical considerations}

This research was conducted in a public hospital in Jambi from April 1, 2019 to April 20, 2019. The researchers explained the objectives, benefits, and research procedures to the patients undergoing hemodialysis. Respondents who showed willingness to involve were requested to complete the informed consent sheets. Respecting the privacy and confidentiality of respondents, providing fair training, benefits, and avoiding dangerous actions were ensured during the study. This research was reviewed and approved by the Health Research Ethics Commission of the Faculty of Medicine, Universitas Padjadjaran with the number 349/UN6.KEP/EC/2019.

\section{RESULTS}

\section{Characteristics of respondents}

The results showed that the characteristics of respondents in both groups had the same level of variation (homogeneous). Respondents in the intervention and control group were the majority aged 36 to 55 years old. However, more women $(61.8 \%)$ were involved in the intervention group compared to the control group which was dominated by men (58.8\%). In addition, most respondents in both groups had neck circumference $<40$ and a BMI of $18.5-22.9$ (Table 1).

Table 1. Characteristics of respondents $(n=68)$

\begin{tabular}{|c|c|c|c|c|c|}
\hline \multirow{3}{*}{ Respondents' Characteristics } & \multicolumn{4}{|c|}{ Group } & \multirow{3}{*}{$p$} \\
\hline & \multicolumn{2}{|c|}{ Intervention $(n=34)$} & \multicolumn{2}{|c|}{ Control $(n=34)$} & \\
\hline & $f$ & $\%$ & $f$ & $\%$ & \\
\hline \multicolumn{6}{|l|}{ Age } \\
\hline $26-35$ years & 6 & 17.6 & 1 & 2.9 & \multirow[t]{5}{*}{$0.121 * *$} \\
\hline 36 - 45 years & 11 & 32.4 & 9 & 26.5 & \\
\hline $46-55$ years & 8 & 23.5 & 12 & 35.3 & \\
\hline 56 - 65 years & 7 & 20.6 & 8 & 23.5 & \\
\hline$>65$ years & 2 & 5.9 & 4 & 11.8 & \\
\hline \multicolumn{6}{|l|}{ Gender } \\
\hline Male & 13 & 38.2 & 20 & 58.8 & \multirow[t]{2}{*}{$0.089 *$} \\
\hline Female & 21 & 61.8 & 14 & 41.2 & \\
\hline \multicolumn{6}{|l|}{ Neck Circumference } \\
\hline$<40 \mathrm{~cm}$ & 24 & 70.6 & 28 & 82.4 & \multirow[t]{2}{*}{$0.253^{*}$} \\
\hline$>40 \mathrm{~cm}$ & 10 & 29.4 & 6 & 17.6 & \\
\hline
\end{tabular}




\begin{tabular}{|c|c|c|c|c|c|}
\hline \multirow{3}{*}{ Respondents' Characteristics } & \multicolumn{4}{|c|}{ Group } & \multirow{3}{*}{$p$} \\
\hline & \multicolumn{2}{|c|}{ Intervention $(n=34)$} & \multicolumn{2}{|c|}{ Control $(n=34)$} & \\
\hline & $f$ & $\%$ & $f$ & $\%$ & \\
\hline Body Mass Index (BMI) & 6 & 17.65 & 4 & 11.8 & $0.587 * *$ \\
\hline $\mathrm{BMI}<18.5$ & 13 & 38.23 & 16 & 47.1 & \\
\hline BMI $18.5-22.9$ & 8 & 23.53 & 3 & 8.8 & \\
\hline BMI $23-24.9$ & 7 & 20.59 & 10 & 29.4 & \\
\hline BMI $25-29.9$ & 0 & 0 & 1 & 2.9 & \\
\hline $\mathrm{BMI}=30$ & & & & & \\
\hline
\end{tabular}

\section{Risk of Obstructive Sleep Apnea (OSA)}

The results showed that there was no difference in the OSA risk before the intervention (pre-test) between the intervention and control groups $(p=0.215)$, indicating that the baselines of OSA risk score in the two groups were the same (Table 2). There was a higher decrease in the frequency of OSA risk on the 4th (post-test 1) and 7th (post-test 2) days after the intervention compared to the control group. After the intervention, most respondents in the intervention group had a decreased risk of OSA (8.8\%), while the control group had an increased risk of OSA (61.8) (Table 2).

Table 2. Risks of Obstructive Sleep Apnea (OSA)

\begin{tabular}{lccccccccc}
\hline & \multicolumn{2}{c}{ Pretest } & \multicolumn{2}{c}{ Post-test 1 } & \multicolumn{4}{c}{ Post-test 2 } \\
& \multicolumn{2}{c}{$f(\%)$} & \multicolumn{2}{c}{$f(\%)$} & \multicolumn{4}{c}{$f(\%)$} \\
\hline
\end{tabular}

\section{Differences in the mean of risk score of Obstructive Sleep Apnea OSA}

The results showed that there were significant differences in the mean of the risk score in the intervention group on day $4(p=0.000)$ and day $7(p=0.003)$ compared to the control group ( $p=0.157$ and $p=0.83$, respectively).

Tabel 3. Differences in the mean of risk score of Obstructive Sleep Apnea (OSA)

\begin{tabular}{|c|c|c|c|c|c|c|}
\hline & \multicolumn{3}{|c|}{$\begin{array}{l}\text { Intervention } \\
\quad(n=34)\end{array}$} & \multicolumn{3}{|c|}{$\begin{array}{l}\text { Control } \\
(n=34)\end{array}$} \\
\hline & $\begin{array}{c}\text { Mean Rank } \\
\text { (Negative) }\end{array}$ & $\begin{array}{c}\text { Sum of } \\
\text { Rank }\end{array}$ & $p$ & $\begin{array}{c}\text { Mean Rank } \\
\text { (Positive) }\end{array}$ & $\begin{array}{c}\text { Sum of } \\
\text { Rank }\end{array}$ & $p$ \\
\hline Pre-test - Post-test 1 & 7.50 & 105.00 & 0.000 & 1.50 & 3.00 & $0.157^{\mathrm{a}}$ \\
\hline Pre test - Post test 2 & 11.50 & 253.00 & 0.000 & 3.00 & 15.00 & 0.025 \\
\hline Post test 1 - Post test 2 & 5.00 & 45.00 & 0.003 & 2.00 & 6.00 & $0.83^{\mathrm{a}}$ \\
\hline
\end{tabular}

Post Hoc Wilcoxon Test, ${ }^{a}$ insignificant difference

\section{Mean differences in the risk score of Obstructive Sleep Apnea (OSA)}

The results showed a significant difference in the OSA risk on day 4 and day 7 between the intervention group $(p=0.000)$ and the control group $(p=0.000)$. The intervention group showed a decreased mean of OSA risk higher than the control group. This meant 
that the intervention group had a tendency to decrease OSA risk greater than the control group.

Table 4. Mean differences in the risk score of Obstructive Sleep Apnea (OSA)

\begin{tabular}{lllrrr}
\hline \multicolumn{1}{c}{ Group } & $n$ & Mean Rank & $\begin{array}{l}\text { Sum of } \\
\text { Rank }\end{array}$ & $p$ \\
\hline Pretest & Intervention & 34 & 32.00 & 1088.00 & $0.219^{\mathrm{a}}$ \\
& Control & 34 & 37.00 & 1258.00 & \\
\hline Post-test 1 & Intervention & 34 & 26.38 & 897.00 & 0.000 \\
& Control & 34 & 42.62 & 1449.00 & \\
\hline Post-test 2 & Intervention & 34 & 22.32 & 759.00 & 0.000 \\
& Control & 34 & 46.68 & 1587.00 & \\
\hline
\end{tabular}

Mann-Whitney Test ${ }^{a}$ insignificant differences

\section{DISCUSSION}

Based on the results of this study, it can be seen that the use of compression stockings (CSs) for a week reduced the risk of OSA in the intervention group compared to the control group, as reported in previous research. Silva et al. (2017) stated that the use of CSs for 1 week is significant in reducing OSA in oliguric/anuric patients in HD patients and can reduce Apnea-Hypopnea Index (AHI) by $19 \%$ with a $4 \%$ reduction in the amount of fluid shifting out of the legs overnight. Meanwhile, White et al. (2015) reported that the use of compression stockings for 2 weeks reduced AHI by $25 \%$ with a $15 \%$ reduction in the amount of fluid that shifted out of the legs overnight. Therefore, it can be concluded that the longer the use of compression stockings, the greater the reduction of OSA risk and the amount of fluid transfer in the legs during the day.

Obstructive Sleep Apnea (OSA) in the patients with excess fluid ranged from moderate to severe OSA risk and accompanied by a significant increase in the amount of fluid in the legs during the day which shifts at night to the neck. This mechanism provides further evidence that overnight rostral fluid shift is one of the factors that contribute to the pathogenesis of OSA in patients with excess fluid (White et al. 2015). In hemodialysis patients, excess fluid contributes to pharyngeal narrowing by vascular distension and/ or due to interstitial edema in the pharyngeal wall or parapharyngeal tissue (Elias et al., 2012). Based on the research of Elias et al. (2012), using magnetic resonance imaging (MRI), OSA severity is correlated with the volume of the jugular vein and the amount of mucous water content around the upper airway in hemodialysis patients. The correlation indicates an important role for excess fluid in the pathogenesis OSA in this population. During the day, while in an upright and sitting position, fluid tends to accumulate in the legs due to gravity. When lying supine at night, water redistributes to the upper body including soft neck tissue, narrows the upper airways, and increases the risk of OSA (Ogna et al., 2015). When moving to the supine position at bedtime, the interstitial fluid that accumulates in the legs is absorbed back into the intravascular compartment and distributed back to the upper body concerning the gravitational force. Some of the fluid that moves from the legs through the stomach is distributed back to the neck at night (Friedman, Bradley, Ruttanaumpawan, \& Logan, 2010; Yumino et al., 2010). The fluid can increase the pressure of the peripharyngeal 
tissue and narrow the upper airways, causing patients to stop breathing during sleep. Beecroft, Pierratos, \& Hanly (2009) also found that excess fluid which is commonly observed in patients with Terminal Kidney Failure (TKF) plays an important role in OSA. As a result, edema is formed in the upper airway and narrows the pharynx.

In the control group, it can be seen that there was an increased risk of OSA on day 7 because the excess fluid in hemodialysis patients contributes to pharyngeal constriction (Elias et al., 2012). Ogna et al. (2015), by comparing pre and post hemodialysis using Polysomnography (PSGs), found a significant correlation between fluid overload volume changes after hemodialysis and OSA severity changes. This shows the significant role of fluid shift and excess fluid, due to the changes in metabolic parameters during hemodialyses, such as $\mathrm{pH}$, BUN, and bicarbonate. When an individual moves from a lying position to a standing position, and increased extracellular volume and a decreased intracellular water occur (Gibson, Beam, Alencar, Zuhl, and Mermier., 2015). Therefore, hydrostatic pressure in the lower limbs goes up. Capillary pressure in the legs when standing $(90-120 \mathrm{cmH} 2 \mathrm{O})$ exceeds the pressure needed to move fluid into the interstitial compartment $(15-20 \mathrm{cmH} 2 \mathrm{O})$ facilitating intravascular volume to decrease $300-400 \mathrm{ml}$. Consequently, fluid shifts from the intravascular and intracellular spaces to the extracellular volume of the lower limb (Silva et al., 2017). In contrast, a lot of fluid is in the intravascular space when using CSs so fluid shifting to the neck at night will be reduced

Compression Stockings (CSs) are a widely used treatment for varicose veins and edema by applying pressure to the legs and reducing fluid movement from intravascular to the interstitial space by preventing capillary hydrostatic pressure (White et al., 2015). Avoiding the accumulation of fluid in the legs during the day using compression stockings can prevent fluid shifts overnight because compression provided by CSs increases intravascular pressure, thereby reducing capillary fluid filtration in the legs (Partsch, Flour, Smith, \& International Compression Club, 2008). This research used a pressure of $30-40 \mathrm{mmHg}$ as $\mathrm{CSs}$ of $30-40 \mathrm{mmHg}$ are more effective than low and medium pressure CSs (Nelson \& Bell-Syer, 2012). The claim is supported by Lim \& Davies (2014) using infrared spectroscopy to monitor the changes in tissue oxyhemoglobin and deoxyhemoglobin. The research reports that oxygenation of the extremities increases with the use of gradual CS especially using high pressure. Therefore, using 30-40 mmHg CSs is expected to reduce the risk of OSA in addition to improving blood circulation in hemodialysis patients. CSs prevent the movement of fluid from the stem to the lower limbs and also from the intracellular to the extracellular space of the torso. The upward pressure exerted by CS partially counteracts gravitational forces avoiding swelling of the legs and maintains more fluid in the intracellular space, which tends to move freely to other areas of the body. As a result, there is a reduction in the amount of fluid reaching the neck, preventing a buildup of edema in the upper airway at night (Silva et al., 2017).

The result also showed that using compression stockings for one week reduces the risk of OSA. This may be due to a decrease in fluid accumulation in the leg. Redolfi et al. (2011a) reported that there is a reduction on the daytime fluid accumulation in the legs by $300 \mathrm{ml}$, overnight rostral fluid transfer by $308 \mathrm{ml}(60 \%)$, and overnight changes in 
neck circumference by $0.7 \mathrm{~cm}$ with a $36 \%$ reduction on AHI of non-obese subjects after using CSs for 7 days compared to the control group. Silva et al. (2017) also stated that there was a decrease in fluid volume of $150 \mathrm{ml}$ after using CSs and reducing Total Body Water (TBW) by $600 \mathrm{ml}$ despite the same body weight between groups. This causes little fluid to be available to move rostral, and reduce the increase in NC. Furthermore, CSs can avoid translocation of fluid from the stem to the legs during the day which increases diurnal diuresis thereby reducing TBW.

Although the proportion of sex between the intervention and control groups in this study was quite different, the male and female have the same risk of developing OSA (Windi, Yonathan, Theresia, \& Finny, 2018). Research by Feng \& Chen, (2009) states that OSA patients are male and female with the same odds ratio for OSA. It is also supported by Tori, Suryawati, \& Husni, (2018). They reported that gender differences do not affect the degree of OSA. In conclusion, the gender proportion in the intervention and control groups did not affect the results.

This study has limitations. During the study, the sleeping position of patients while sleeping at home could not be controlled. Some factors affecting the incidence of OSA such as the degree of excess fluid in each patient, dry weight, and patient albumin were also not controlled.

\section{CONCLUSION}

This study concluded that there were effects of $30-40 \mathrm{mmHg}$ CSs on the risk score of Obstructive Sleep Apnea (OSA) in hemodialysis patients. This research recommends CSs as a safe and simple intervention to prevent risks of OSA in hemodialysis patients. Further research on the effects of CSs is recommended by modifying the interventions, adding variables, comparing CSs pressure, and utilizing a larger sample size.

\section{ACKNOWLEDGEMENT}

The researchers would like to thank all respondents participating in this study and the hospital where the study was taken place.

\section{CONFLICT OF INTEREST}

No conflicts of interest in this study were declared by the authors.

\section{REFERENCES}

Abuyassin, B., Sharma, K., Ayas, N. T., \& Laher, I. (2015). Obstructive sleep apnea and kidney disease: A potential bidirectional relationship?. Journal of Clinical Sleep Medicine, 11(8), 915-924. doi:10.5664/jcsm.4946

Anwar, S. H., Tursina, A., \& Rosady, D. S. (2017). Hubungan indeks massa tubuh dan lingkar leher dengan kejadian obstructive sleep apnea pada stroke iskemik [Correlation between body mass index (BMI) and obstructive sleep apnea in ischemic stroke patients]. Bandung Meeting on Global Medicine \& Health (BaMGMH), 1(1), 68-72.

Beecroft, J. M., Pierratos, A., \& Hanly, P. J. (2009). Clinical presentation of obstructive sleep apnea in patients with end-stage renal disease. Journal of Clinical Sleep Medicine, 5(02), 115-121. doi:10.5664/jcsm.27438 
Budiarsa, I. (2016). Obstructive sleep apnea pada lansia [Obstructive sleep apnea in the elderly]. Retrieved from https://simdos.unud.ac.id/uploads/file_penelitian_1_dir/3b3ab1955520fae7539c58 d4e9a325e7.pdf

Chung, F., Yegneswaran, B., Liao, P., Chung, S., Vairavanathan, S., Islam, S., ..., \& Shapiro, C. (2008). STOP Questionnaire. Anesthesiology, 108(5): 812-21. doi:10.1097/ALN.0b013e31816d83e4

dos Reis Santos, I., Danaga, A. R., de Carvalho Aguiar, I., Oliveira, E. F., Dias, I. S., Urbano, J., ..., Oliviera, L. V. (2013). Cardiovascular risk and mortality in endstage renal disease patients undergoing dialysis: sleep study, pulmonary function, respiratory mechanics, upper airway collapsibility, autonomic nervous activity, depression, anxiety, stress and quality of life: a prospective, double blind, randomized controlled clinical trial. BMC Nephrology, 14, 215. doi:10.1186/1471-2369-14-215

Elias, R. M., Chan, C. T., Paul, N., Motwani, S. S., Kasai, T., Gabriel, J. M., ..., \& Bradley, T. D. (2012). Relationship of pharyngeal water content and jugular volume with severity of obstructive sleep apnea in renal failure. Nephrology Dialysis Transplantation, 28(4), 937-944. doi:10.1093/ndt/gfs473

Feng, J., \& Chen, B. Y. (2009). Prevalence and incidence of hypertension in obstructive sleep apnea patients and the relationship between obstructive sleep apnea and its confounders. Chinese medical journal, 122(12), 1464-1468. doi:10.3760/cma.j.issn.0366-6999.2009.12.021

Friedman, O., Bradley, T. D., Ruttanaumpawan, P., \& Logan, A. G. (2010). Independent association of drug-resistant hypertension to reduced sleep duration and efficiency. American journal of hypertension, 23(2), 174-179. doi:10.1038/ajh.2009.220

Gibson, A. L., Beam, J. R., Alencar, M. K., Zuhl, M. N., \& Mermier, C. M. (2015). Time course of supine and standing shifts in total body, intracellular and extracellular water for a sample of healthy adults. European Journal of Clinical Nutrition, 69(1), 14-19. doi:10.1038/ejen.2013.269

Indonesian Renal Registry (IRR). (2018). 11th report of Indonesian renal registry. Accessed on June 17, 2020. Retrieved from https://www.indonesian renalregistry.org

International Society of Lymphology. (2013). The diagnosis and treatment of peripheral lymphedema: 2013 Consensus Document of the International Society of Lymphology. Lymphology, 46(1), 1-11. Retrieved from https://pubmed.ncbi.nlm.nih.gov/23930436/

Lim, C. S., \& Davies, A. H. (2014). Graduated compression stockings. Canadian Medical Association Journal, 186(10), E391-E398.

Ministry of Health Republic of Indonesia (2013). Laporan nasional riskesdas, prevelensi gagal ginjal kronik di Indonesia [The national report of basic health research, the prevalence of chronic kidney disease in Indonesia]. Accessed on December 10, 2018. Retrieved from http://depkes.go.id

Kerns, E. S., Kim, E. D., Meoni, L. A., Sozio, S. M., Jaar, B. G., Estrella, M. M., ..., Bourjeily, G. (2018). Obstructive sleep apnea increases sudden cardiac death in incident hemodialysis patients. American Journal of Nephrology, 48(2), 147-156. doi:10.1159/000489963 
Nelson, E. A., \& Bell-Syer, S. E. (2012). Compression for preventing recurrence of venous ulcers. Cochrane Database of Systematic Reviews, (9). doi:10.1002/14651858.CD002303.pub3

Ogna, A., Forni Ogna, V., Mihalache, A., Pruijm, M., Halabi, G., Phan, O., \& Heinzer, R. (2015). Obstructive sleep apnea severity and overnight body fluid shift before and after hemodialysis. Clinical Journal of the American Society of Nephrology, 10(6), 1002-1010. doi:10.2215/CJN.08760914

Özdemir, Ö. C., Sevim, S., Duygu, E., Tuğral, A., \& Bakar, Y. (2016). The effects of short-term use of compression stockings on health related quality of life in patients with chronic venous insufficiency. Journal of physical therapy science, 28(7), 1988-92. doi:10.1589/jpts.28.1988

Partsch, H., Flour, M., Smith, P. C., \& International Compression Club (2008). Indications for compression therapy in venous and lymphatic disease consensus based on experimental data and scientific evidence. Under the auspices of the IUP. International Angiology: A Journal of the International Union of Angiology, 27(3), 193-219.

Redolfi, S., Arnulf, I., Pottier, M., Lajou, J., Koskas, I., Bradley, T. D., \& Similowski, T. (2011a). Attenuation of obstructive sleep apnea by compression stockings in subjects with venous insufficiency. American journal of respiratory and critical care medicine, 184(9), 1062-1066. doi:10.1164/rccm.201102-03500C

Redolfi, S., Arnulf, I., Pottier, M., Bradley, T. D., \& Similowski, T. (2011b). Effects of venous compression of the legs on overnight rostral fluid shift and obstructive sleep apnea. Respiratory Physiology \& Neurobiology, 175(3), 390-393. doi:10.1016/j.resp.2011.01.001

Silva, B. C., Santos, R. S., Drager, L. F., Coelho, F. M., \& Elias, R. M. (2017). Impact of compression stockings vs continuous positive airway pressure on overnight fluid shift and obstructive sleep apnea among patients on hemodialysis. Frontiers in Medicine, 4, 57. doi:10.3389/fmed.2017.00057

Tori, M., Suryawati, H., \& Husni, A. (2018). Correlation between anthropometric measurements and stage of obstructive sleep apnea. Neurona (Majalah Kedokteran Neuro Sains Perhimpunan Dokter Spesialis Saraf Indonesia), 35(2), 144-150.

Wali, S. O., Alkhouli, A., Howladar, M., Ahmad, I., Alshohaib, S., Al-Ghamdi, S., \& Krayem, A. (2015). Risk of obstructive sleep apnea among Saudis with chronic renal failure on hemodialysis. Annals of thoracic medicine, 10(4), 263. doi:10.4103/1817-1737.164300

White, L. H., Lyons, O. D., Yadollahi, A., Ryan, C. M., \& Bradley, T. D. (2015). Effect of below-the-knee compression stockings on severity of obstructive sleep apnea. Sleep medicine, 16(2), 258-264. doi:10.1016/j.sleep.2014.12.005

Windi, M., Yonathan, S., Theresia, R., \& Finny, W. (2018). Association between risk of obstructive sleep apnea (OSA) and ischemic stroke incidence in Prof dr Kandou Hospital Manado. Jurnal Neurologi Manado, Sinaps, 1(2), 29-35. Retrieved from http://jurnalsinaps.com/index.php/sinaps/article/view/27

Yumino, D., Redolfi, S., Ruttanaumpawan, P., Su, M. C., Smith, S., Newton, G. E., ..., \& Bradley, T. D. (2010). Nocturnal rostral fluid shift: a unifying concept for the pathogenesis of obstructive and central sleep apnea in men with heart failure. Circulation, 121(14), 1598-1605. doi:10.1161/CIRCULATIONAHA.109.902452 